\title{
Estimating Visual Quality in Skin Pictures Obtained by Optical Cameras and Analysis by Morphological Filters
}

\author{
S. Sree Hari Raju, E.G. Rajan
}

\begin{abstract}
This paper portrays the utilization of morphological channels for breaking down skin surface pictures. The factual boundaries and visual quality proportion of skin pictures caught by optical cameras are given. Morphological channels are blends of the fundamental activities of expansion and disintegration. For example if the activity of widening is spoken to by the image 1 and that of disintegration by 0 , at that point a twofold string 0110 would demonstrate that the morphological tasks of disintegration, two enlargements and one disintegration to be done on a given picture with the equivalent organizing component.
\end{abstract}

Keywords: Morphological filters, Dilation, Erosion, Dermatologist, optical camera.

\section{INTRODUCTION}

Normally skin pictures are acquired utilizing optical cameras. A dermatologist looks at a skin picture utilizing his own visual recognition capacity and structures his emotional clinical assessment about the status of the skin. Not that all emotional conclusions on similar picture by different dermatologists would continue as before, and that is the way one is worried about abstract clinical sentiments. This implies, emotional clinical conclusions may not remain to the correct sort of clinical practices. Also, quality and data substance of pictures of a specific skin gained at various lighting conditions utilizing various cameras may not yield predictable pictures, in the data hypothetical sense. These dermatologists cling to a standard working strategy. In this unique situation, one can generally utilize certain quantifiable measures for analyzing skin pictures during the demonstrative stage. Two quantifiable measures are talked about in this paper, which could be considered as measures while looking at skin pictures. The measures could be utilized in different applications like (I) assessment of pictures when applying sunscreen, (ii) assessment of pictures when a skin medical procedure, (iii) assessment of pictures when applying a picture handling channel. In the first place, essential insights concerning measurable boundaries and visual quality are clarified in beneath areas.

Revised Manuscript Received on October 20, 2020.

* Correspondence Author

S. Sree Hari Raju*, Research Scholar, Dept. of Computer Science, MG-NIRSA, Affiliated to University of Mysore, Manasagangotri, Mysore, Karnataka, India. E-mail: rvs2raju@gmail.com

Prof. E.G. Rajan, Director, MG-NIRSA. E-mail: rajaneg@yahoo.co.in

(C) The Authors. Published by Blue Eyes Intelligence Engineering and Sciences Publication (BEIESP). This is an open access article under the CC BY-NC-ND license (http://creativecommons.org/licenses/by-nc-nd/4.0/) two significant issues could be extensively decreased if all

\section{A. The Notion of Morphological Filters}

The string 0110 speaks to a morphological channel. Fig. 1 shows the skin of a patient and its prepared picture utilizing a morphological channel. This patient was distinguished to be influenced by skin carcinoma.

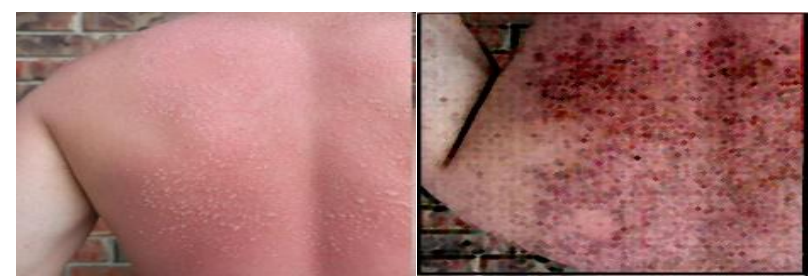

Fig. 1: Skin cancer of a patient and its morphologically filtered version

A morphological channel basically executes the essential activities of enlargement and disintegration, which are characterized as follows.

\section{MORPHOLOGICAL EROSION OF 2-D GRAY / COLOR IMAGES}

For any two gray-level or color images $\mathrm{A}$ and $\mathrm{B}$, the morphological erosion is defined as

$$
\mathrm{E}(\mathrm{A}, \mathrm{B})=\mathrm{A} \theta \mathrm{B}=\mathrm{INF}_{(\mathrm{xy}) \in \mathrm{DB}}\left[\mathrm{A}_{-\mathrm{x}, \mathrm{y}}+\mathrm{B}(\mathrm{x}, \mathrm{y})\right]
$$

where $D_{B}$ is the domain of the image $B$, and INF is an operation of infimumor minimum over the intersections of the domains. The algorithm for implementing the operation of erosion is given below.

\section{A. Algorithm for Erosion of Grayscale and Color Images}

Continue sliding the organizing component over the picture \{

deduct pixels of organizing component from the relating pixels of the picture, locate the base, $k$, among every one of them if all the organizing component pixels are not exactly the relating picture pixels at that point supplant the focal pixels in the picture with $\mathrm{k}$; else supplant it with 0 \}

until the organizing component traverses entire of the picture

\section{B. Morphological Dilation of 2-D Gray / Color Images}

For any two gray-level digital images $\mathrm{A}$ and $\mathrm{B}$, the dilation is defined as

$$
\mathrm{D}(\mathrm{A}, \mathrm{B})=\mathrm{A} \oplus \mathrm{B}=\operatorname{EXTSUP}_{(\mathrm{x}, \mathrm{y}) \in \mathrm{BB}}\left[\mathrm{A}_{\mathrm{x}, \mathrm{y}}+\mathrm{B}(\mathrm{x}, \mathrm{y})\right]
$$

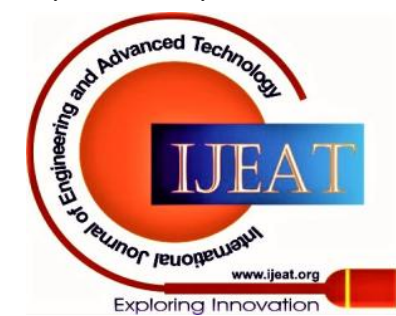




\section{Estimating Visual Quality in Skin Pictures Obtained by Optical Cameras and Analysis by Morphological}

Filters

where $D_{B}$ is the domain of the image $B$, and EXTSUP is an operation of supremumor maximum over the union of the domains.

\section{Algorithm for Dilation of Grayscale and Color Images}

Continue sliding the organizing component over the picture \{ add pixels of organizing component to the comparing pixels of the picture discover themost extreme, $\mathrm{k}$, among every one of them if at any rate one of the picture pixels that are traversed by organizing component is non-zero at that point supplant the focal pixels in the picture with $\mathrm{k}$; else supplant it with 0

\}

until the organizing component traverses entire of the picture

\section{The Notions of Opening and Closing of Images}

To buildOpening and Closingoperations we need to combinedilation and erosion.

Opening is expansion trailed by disintegration and characterized as $\mathrm{A} \bullet \mathrm{B}=(\mathrm{A} \theta \mathrm{B}) \oplus \mathrm{B}$. Shutting is disintegration trailed by widening and characterized as $\mathrm{A} \circ \mathrm{B}=(\mathrm{A} \oplus \mathrm{B}) \theta \mathrm{B}$. Opening and shutting are known as morphological channels. Morphological activities show various arithmetical properties and the whole hypothesis of numerical morphology falls under the classification of what is called as Image Algebra. In this specific circumstance, a concise thought of Minkowski variable based math is sketched out underneath.

\section{E. Minkowski Algebra of Analog Morphology}

Polynomial math of Euclidean (simple) morphology is basically the Minkowski variable based math. This is additionally alluded to as picture variable based math. Properties of this variable based math include the fundamental set hypothetical tasks of association (dilation), crossing point (erosion) and complementation. In this mathematical structure, one can create calculations for handling 2D pictures. Certain properties of Minkowski polynomial math are quickly clarified in the accompanying. Dilation $\mathrm{t}$ fulfills an extraordinary type of associativity $\mathrm{A} \oplus(\mathrm{B}+\mathrm{x})=(\mathrm{A} \oplus \mathrm{B})+\mathrm{x}$, which is generally additionally called as interpretation invariance of dilation

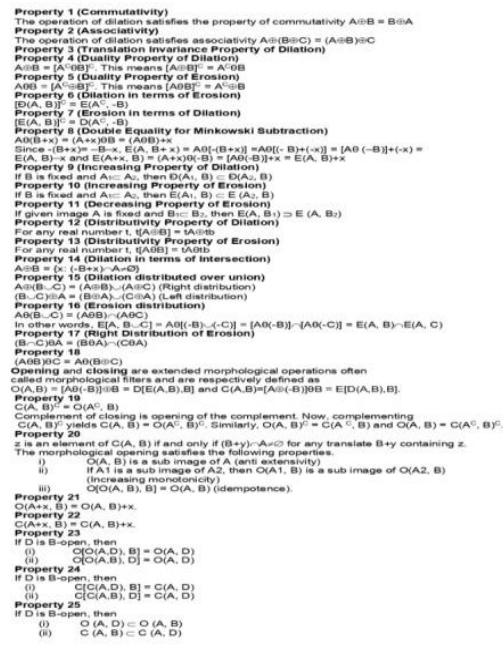

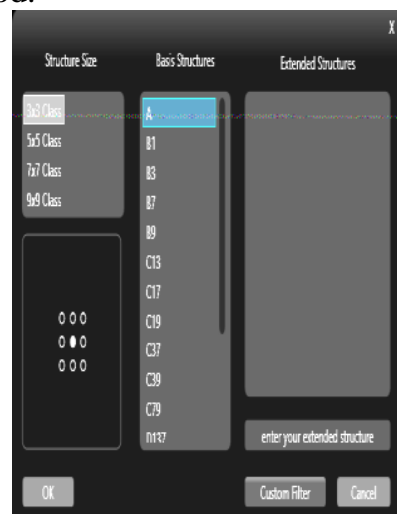

Structuring element $A$ in 3x3 neighborhood
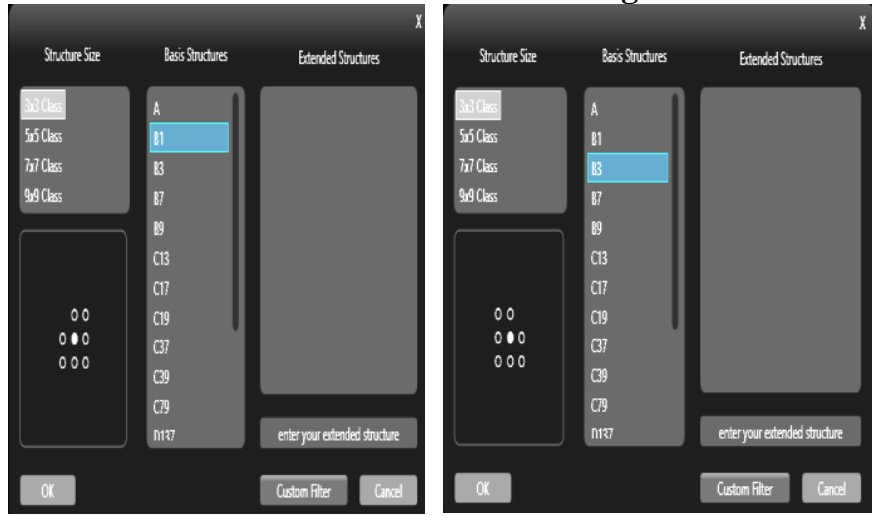

Structuring element B1 in $3 \times 3$ neighborhood

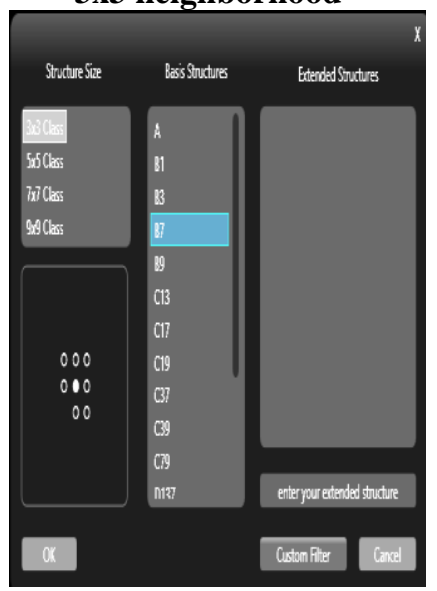

Structuring element B3 in 3x3 neighborhood

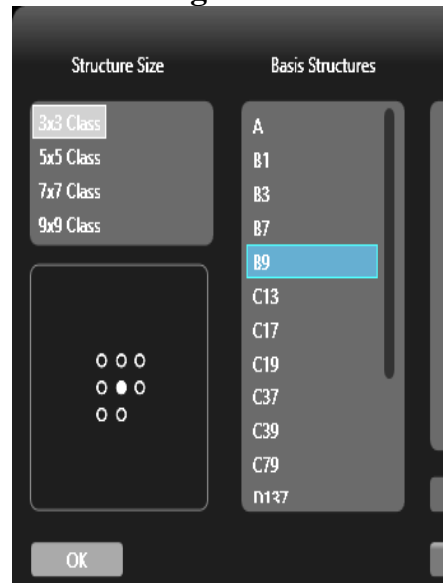

Structuring element B7 in $3 \times 3$ neighborhood

Structuring element B9 in 3x3 neighborhood Continued... 


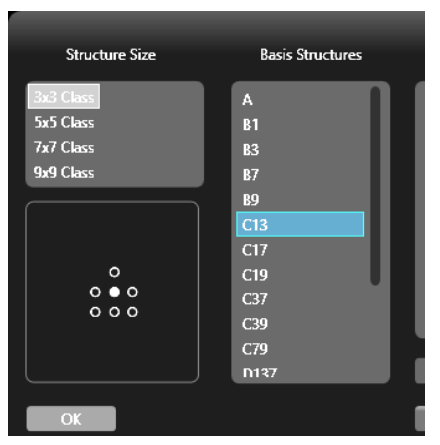

Structuring element C13 in $3 \times 3$ neighborhood

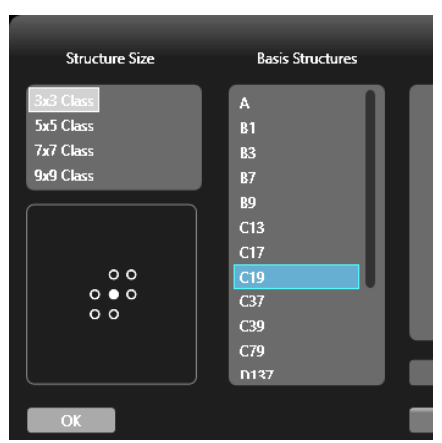

Structuring element C19 in $3 \times 3$ neighborhood

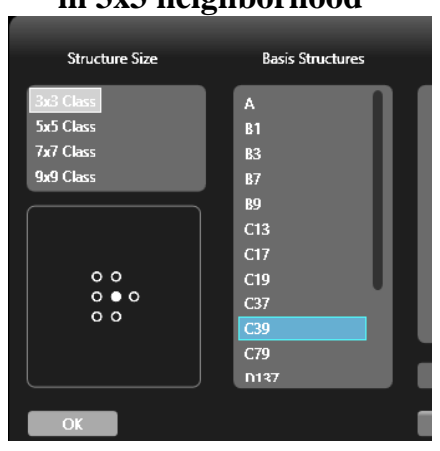

Structuring element C39 in $3 \times 3$ neighborhood

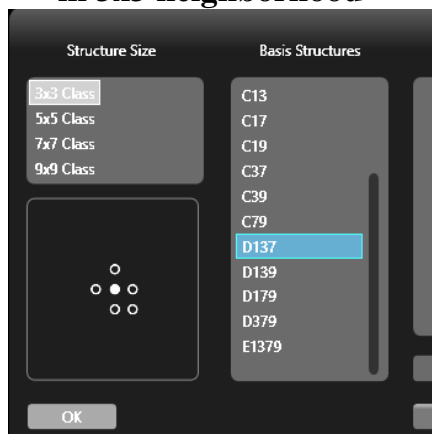

Structuring element D137 in $3 \times 3$ neighborhood

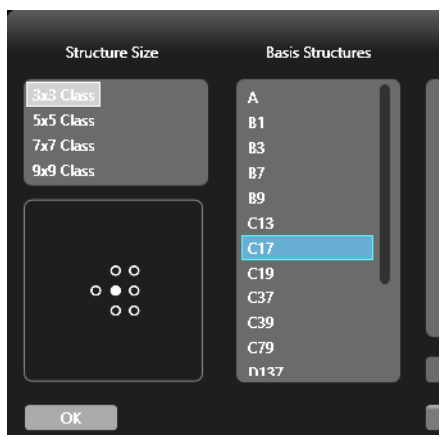

Structuring element C17 in $3 \times 3$ neighborhood

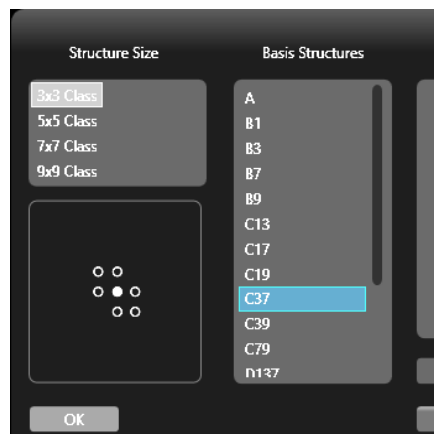

Structuring element C37 in $3 \times 3$ neighborhood

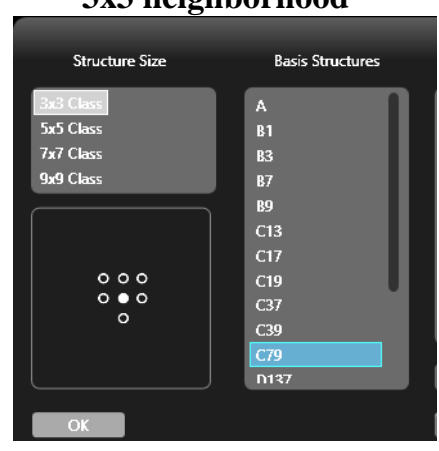

Structuring element C79 in $3 \times 3$ neighborhood

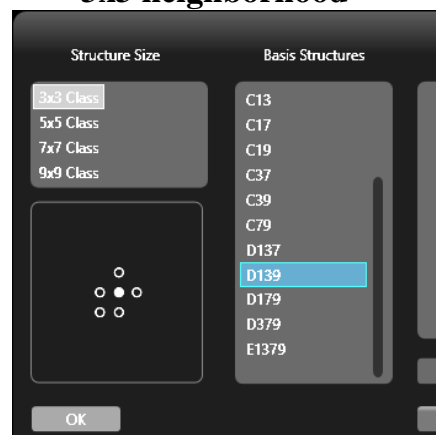

Structuring element D139 in $3 \times 3$ neighborhood Continued..
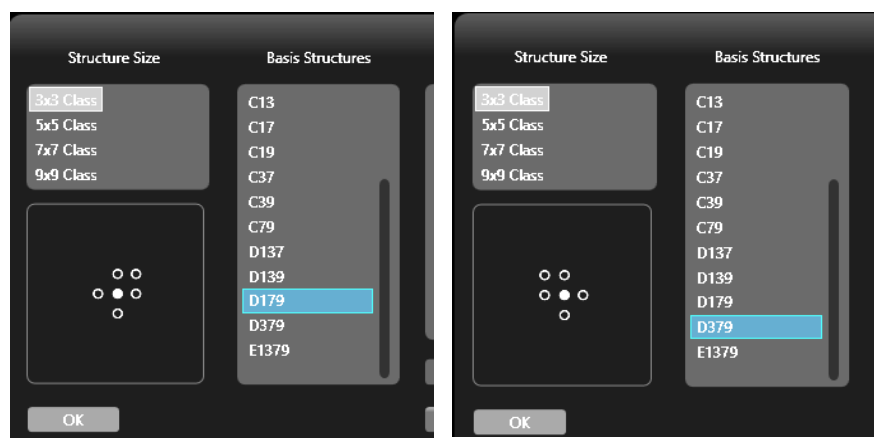

Structuring element D179 in $3 \times 3$ neighborhood

Structuring element D379 in $3 \times 3$ neighborhood

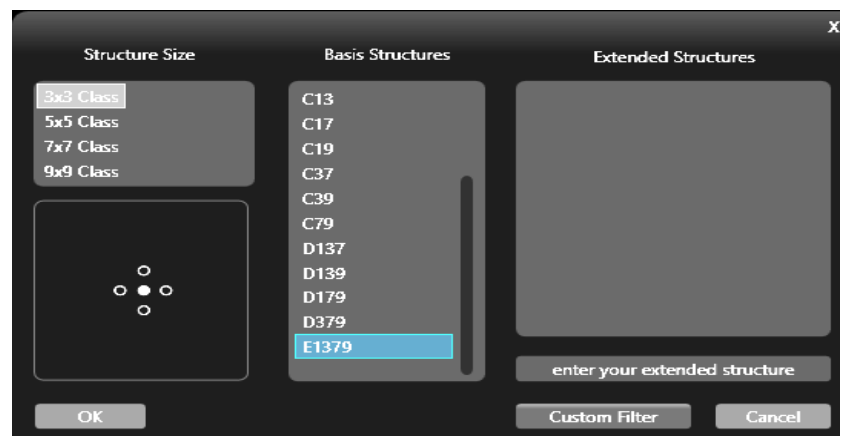

Structuring element E1379 in 3x3 neighborhood

Fig. 2 : Sixteen polygons in a $3 \times 3$ neighborhood All the sixteen raised polygons are gotten by eliminating every one of the four corner pixels, each in turn, two all at once, three all at once and every one of the four all at once.

One can have a sum of 256 organizing components in a 3x3 neighborhood. All things considered, one would utilize just sixteen arched polygons as organizing components while completing morphological sifting activities.

Similar to the sixteen structuring elements formed in a $3 \times 3$ neighborhood, one can constrcut structuring elements in $5 \times 5,7 \times 7$ and $9 \times 9$ neighborhoods also. Fig. 3 shows some sample strcturing elements formed in 5x5 neighborhood.

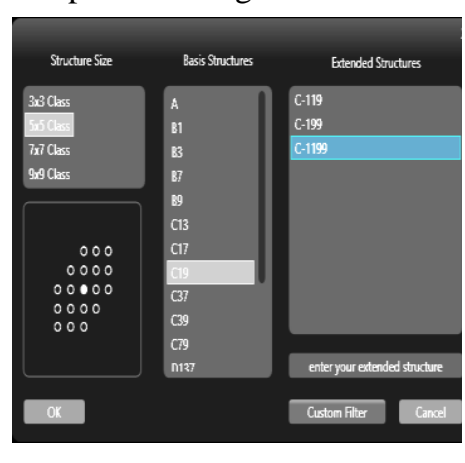

Structuring element C1199 in $5 \times 5$ neighborhood

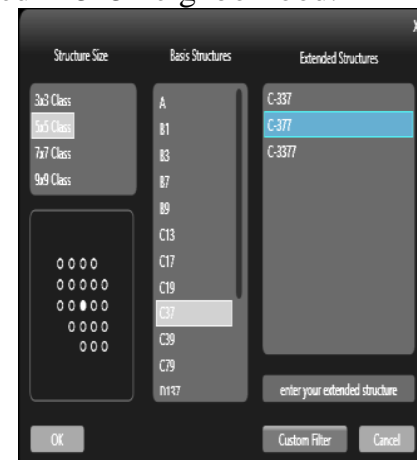

Structuring element C377 in 5x5 neighborhood

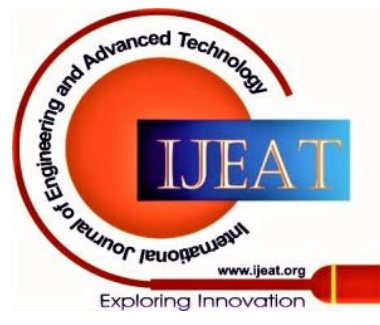




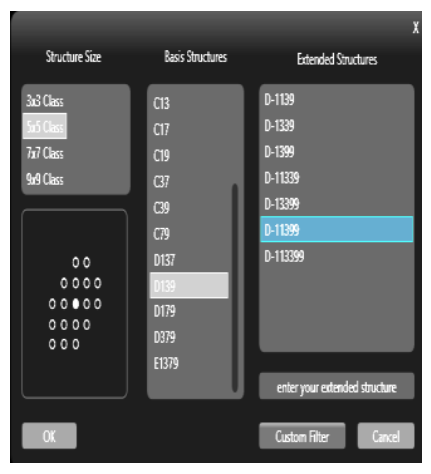

Structuring element D11399 in $5 \times 5$ neighborhood

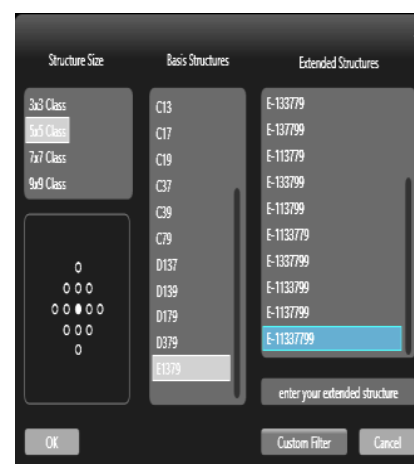

Structuring element

E11337799 in 5x5

neighborhood
Fig. 3: Some convex polygons in a $5 \times 5$ neighborhood

Fig. 4 and Fig. 5 respectively show some convex polygons constructed in $7 \times 7$ and $9 \times 9$ neighborhoods.

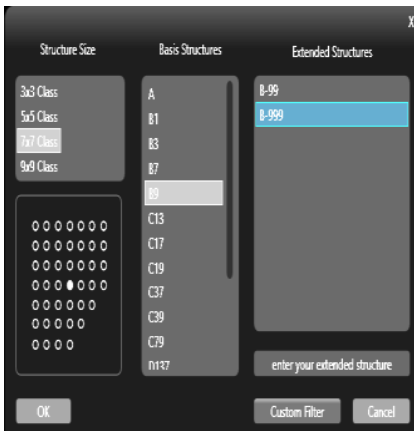

Structuring element B999 in $7 \times 7$ neighborhood

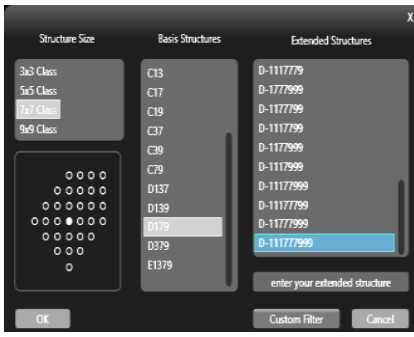

Structuring element D111777999 in 5x5 neighborhood

Fig. 4: Some convex polygons in a 7x7 neighborhood

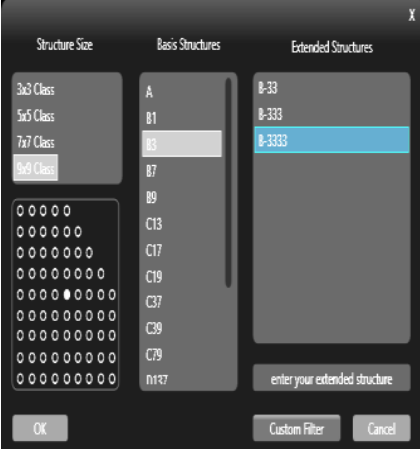

Structuring element B3333 in 9x9 neighborhood

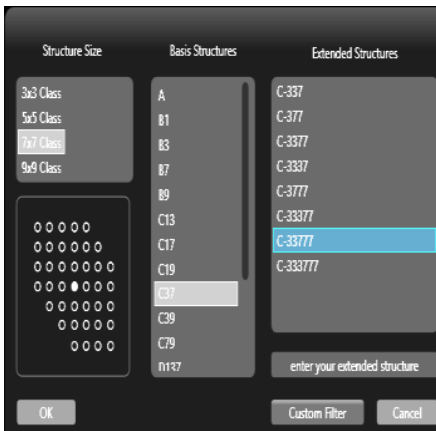

Structuring element C33777 in 7x7 neighborhood

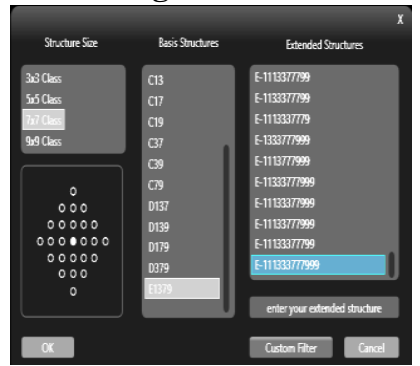

Structuring element

E111333777999 in 5x5 neighborhood

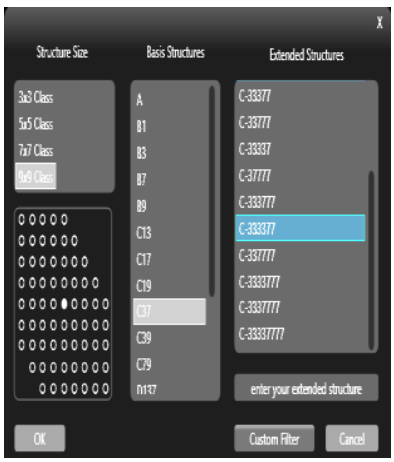

Structuring element C333377 in 9x9 neighborhood

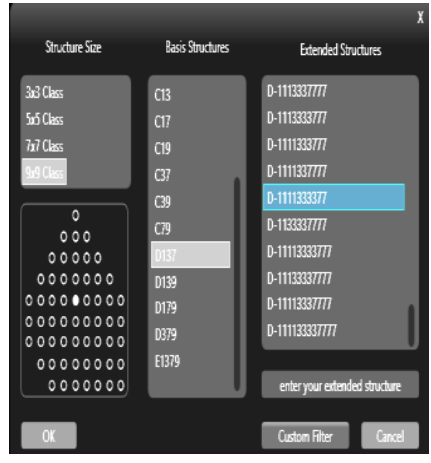

\section{Structuring element}

D1111333377 in 9x9

neighborhood

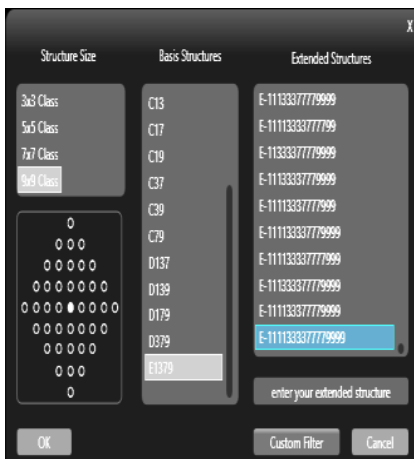

Structuring element E1111333377779999 in 9x9 neighborhood
Fig. 5: Some convex polygons in a 9x9 neighborhood Structuring elements in a neighborhood form a lattice $\Phi=<$ $\mathrm{X}, \subseteq>$, where $\mathrm{X}$ is the set of all structuring elements (convex polygons) in that neighborhood and $\subseteq$ is the binary partial order relation of 'inclusion'. Fig. 6 shows a lattice $\Phi_{3 \times 3}=<X_{3 \times 3}, \subseteq>$, where $X_{3 \times 3}$ is the set of sixteen convex polygons in $3 \times 3$ neighborhood.

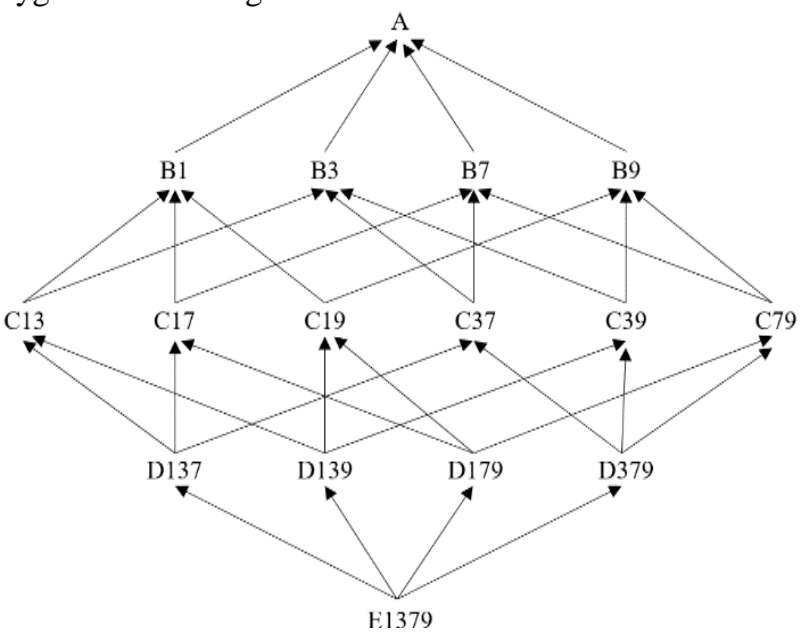

Fig. 6: Lattice formed by 16 convex polygons in $3 \times 3$ neighborhood

With reference to Fig. 6, one can construct 24 maximal linear chains starting from E1379 to A

\section{IV. \\ USE OF MORPHOLOGICAL FILTERS IN IMAGE PROCESSING}

Morphological channels could be utilized to handle skin pictures so as to extricate different concealed highlights like injuries, shading normal, shapes, surfaces, to give some examples. Fig. 7 shows a progression of activities completed on an example skin picture and consequences of applying morphological channels.

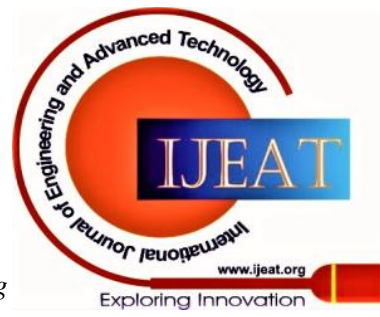




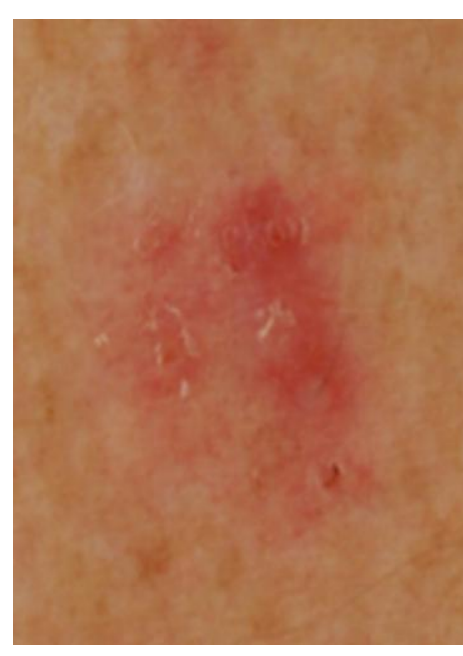

(a) Sample skin image

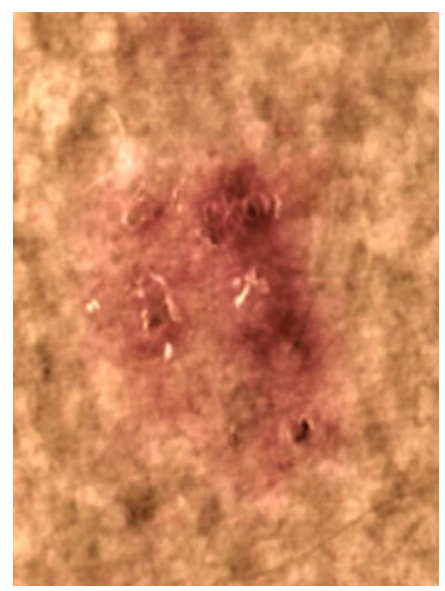

(c) Image dyadically multiplied with blue component

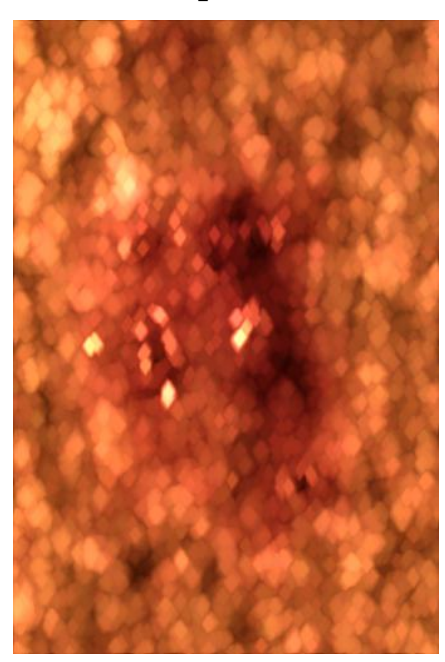

(e) Image (d) processed with $5^{\text {th }}$ order filter 11111 using structuring element $\mathbf{E}_{1379}$

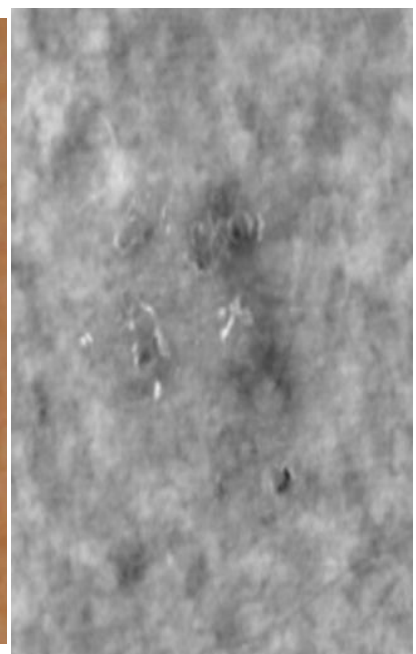

(b) Blue component of the image (a)

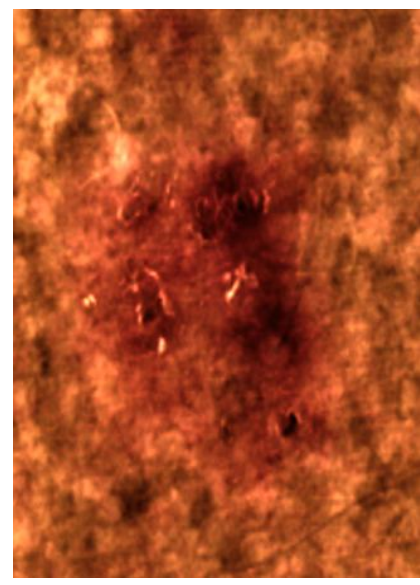

(d) Pixel wise squared image of (c)

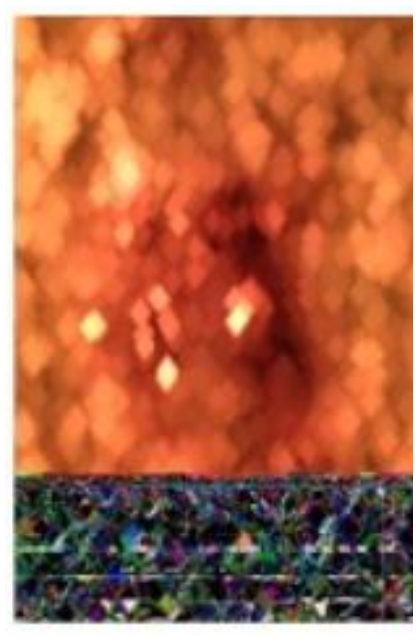

(f) Image (d) processed with $1^{\text {th }}$ order filter

1111111111

using structuring element $E_{1379}$

Fig. 7: Sample skin image processed with morphological filters

V. IMAGES to study a digital image are given below.

Pixels Count (size of the image), Pixels without black (foreground pixels), Red Min (minimum red component value in the image), Red Max, Red Mean, Red Standard Deviation, Red Median, Red Total Count, Green Min, Max, Green Mean, Green Standard Deviation, Green Luminance Min, Luminance Max, Luminance Mean, Luminance Standard Deviation, Luminance Median, Y Min, Y Max, Y Mean, Y Standard Deviation, Y Median, Cb Min, $\mathrm{Cb}$ Max, Cb Mean, Cb Standard Deviation, Cb Median, Cr Min, Cr Max, Cr Mean, Cr Standard Deviation, Cr Median, Red Min WB, Red Max WB, Red Mean WB, Red Standard Deviation WB, Red Median WB, Red Total Count WB, Green Min WB, Green Max WB, Green Mean WB, Green Standard Deviation WB, Green Median WB, Green Total Count WB, Blue Min WB, Blue Max WB, Blue Mean WB, Count WB, Saturation Min WB, Saturation Max WB, Saturation Mean WB, Saturation Standard Deviation WB Saturation Median WB, Luminance Min WB, Luminance Deviation WB, Luminance Median WB, Y Min WB, Y Max WB, Y Mean WB, Y Standard Deviation WB, Y Median WB, Cb Min WB, Cb Max WB, Cb Mean WB, Cb Standard Deviation WB, Cb Median WB, Cr Min WB, Cr Max WB, Cr Mean WB, Cr Standard Deviation WB, Cr Median WB

One example of both correct and incorrect white balance is given in Fig. 8

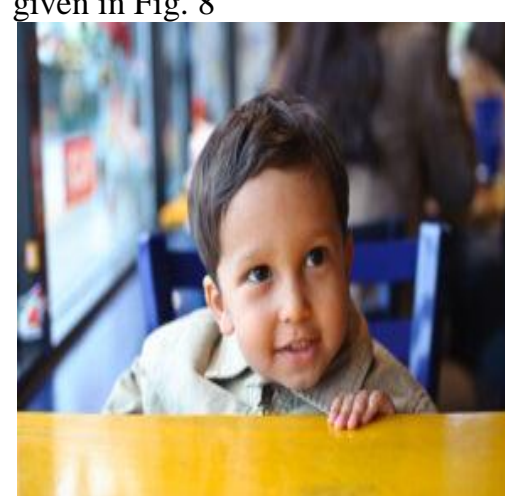

Image with white balance

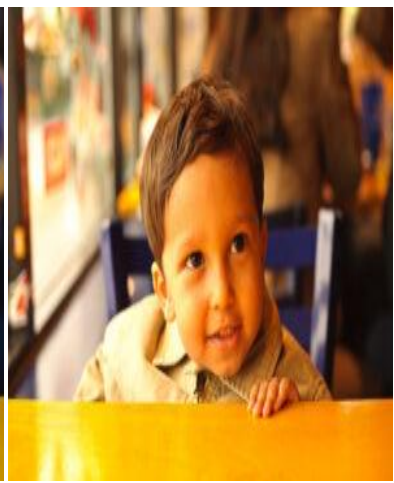

Image without white balance

Table 8 shows some values of all statistical parameters associated with image, with white balance shown in Fig. 8.

For comparison purposesRed Median, Green Median and Blue Medianparametric values must consider for skin images.

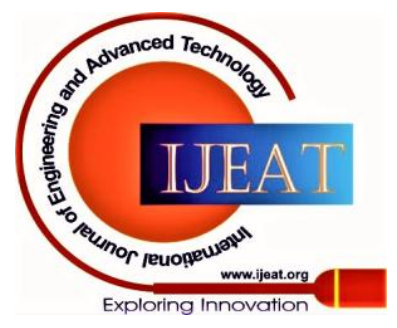




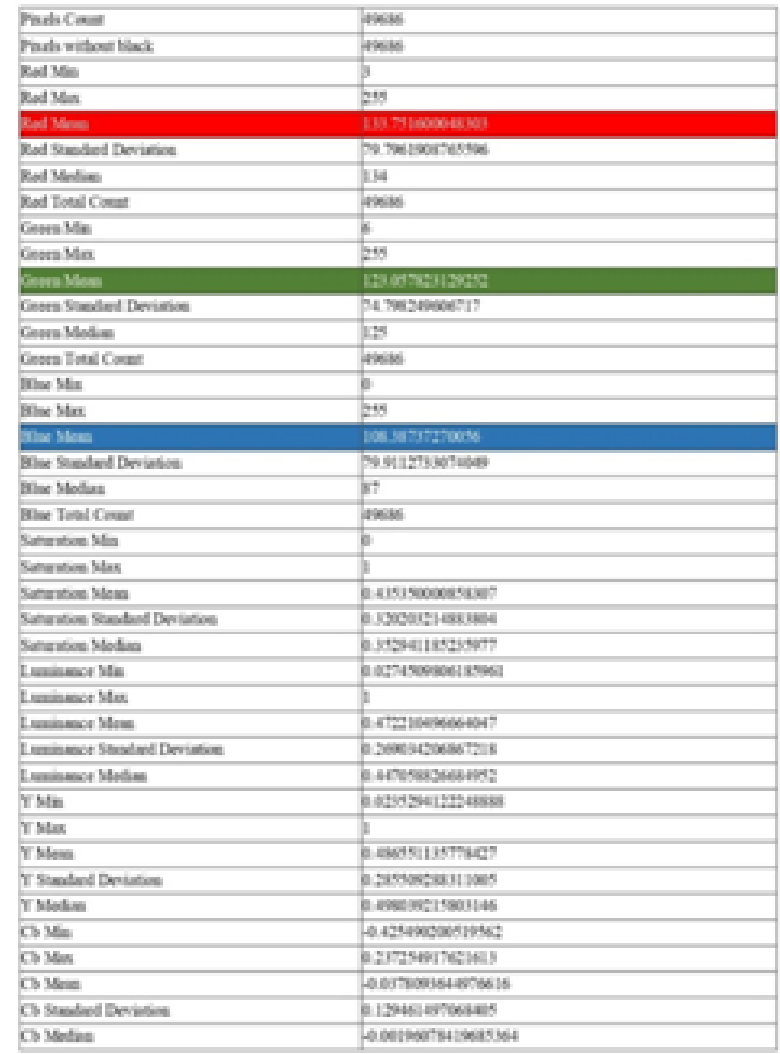

Table 8: Statistical values of image shown in Fig. 8.

\section{HUMAN VISUAL QUANTIZATION THRESHOLD - A VISUAL QUALITY MEASURE}

A profound psycho-physiological investigation of the human visual cortex has drawn out a perception that the visual substance introduced to the 'V1 region' of the 'visual cortex' is perceived by that territory regarding limits (edges) of different fragments contained in the detected picture. These sections are isolated by visual quantization of $81 \%$ practiced by the V1 territory and the particular shapes (edges) extricated. This sifting property of the V1 zone of the visual cortex is known as 'Human Visual Quantization' (HVQ)'. The HVQ of $81 \%$ of the zero entropy visual mode where visual quality VQ is $100 \%$ is utilized here to decide the ideal limit for edge based picture handling tasks. Fig. 6.2 shows an example computerized picture debased by spot commotion and its HVQT esteem assessed utilizing the HVQT calculation given underneath.

\section{HVQT Algorithm}

- Instate a predefined (Counter worth is 0)

- $\quad$ Sweep a given picture by a 3x3 window

- At each picture pixel position locate the greatest power an incentive in the area characterized by window

- At each picture pixel position locate the base force an incentive in the area characterized by window

- At each picture pixel position compute the greatest force esteem - least power esteem

- At each picture pixel position check whether this force contrast is not exactly or equivalent to an edge $T$

- At each picture pixel position on the off chance that this condition is valid, at that point increase the incentive in the counter
- At each picture pixel position on the off chance that this condition isn't fulfilled, at that point proceed onward to the following pixel

- $\quad$ Do this till the whole picture is filtered

- The counter worth is treated as visual quality

- $\quad$ Do this test for limit T differing from 0 to 255

Draw a diagram interfacing edge esteems in the $\mathrm{x}$-pivot and counter qualities in the $y$-hub

Note: $0 \%$ visual quality methods the picture is absolutely arbitrary; $100 \%$ visual quality methods zero entropy picture.

Result:81\% visual quality level line that cuts the visual quality bend indicates HVQT estimation of the picture.

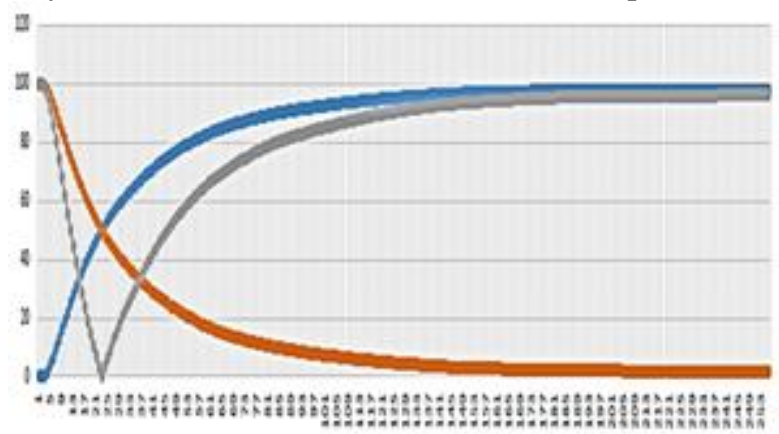

Fig. 9: Graph connecting visual quality, entropy and theirdifferences

The quantificational measures are assessed for face pictures of a lady when applying sunscreen cream all over and results introduced in the following section. In this way, the quantificational measures are assessed for a lot of nine skin pictures, as a total contextual investigation, and aftereffects of the examination introduced in different parts.

\section{OBSERVATIONS AND CONCLUSIONS}

1. Unique skin picture with suspected skin carcinoma doesn't show any extreme side effect of skin carcinoma. A dermatologist may close his perception with a bogus negative.

2. The blue part of the picture features the potential outcomes of skin carcinoma

3. Test picture duplicated with the blue segment shows positive outcome

4. Pixel savvy squared picture invalidates bogus positive and bogus negative outcomes

5. Picture prepared with fifth request channel 11111 utilizing organizing component E1379 gurantees the presence of skin carcinoma in the skin

6. Picture prepared with tenth request channel 1111111111 utilizing organizing component E1379 gurantees the presence of skin carcinoma in the skin and furthermore presents the future groth of the skin carcinoma

7. Rank surfaces of the skin picture obviously display the presence of skin carcinoma

8. This strategy could be normalized as an analytic apparatus of skin carcinoma by dermatologists.

9. Complete hypothetical defense will be given in the theory

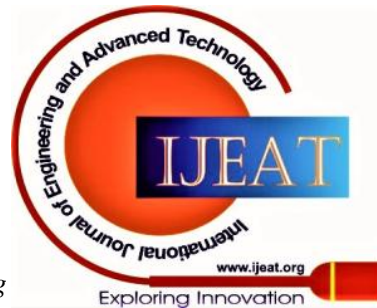


Endeavors were made to contemplate use instances of continuous skin pictures and a similar report made with other existing techniques. Aside from surfaces and other skin highlights, one can order skin pictures dependent on their visual characteristics. Visual quality is an emotional gauge and till now there is no proper system in which skin quality is surveyed. Two methodologies called (i) reference strategy and (ii) no reference technique could be utilized dependent on specific suppositions.

\section{REFERENCES}

1. Maton, Anthea; Jean Hopkins; Charles William McLaughlin; Susan Johnson; MaryannaQuon Warner; David La Hart; Jill D. Wright (1893). Human Biology and Health. Englewood Cliffs, New Jersey, USA: Prentice Hall. ISBN 978-0-13-981176-0.

2. Wilkinson, P.F. Millington, R. (2009). Skin (Digitally printed version ed.). Cambridge: Cambridge University Press. pp. 49-50. ISBN 9780-521-10681-8.

3. Bennett, Howard (25 May 2014). "Ever wondered about your skin?". The Washington Post. Retrieved 27 October 2014.

4. Stücker, M.; A. Struk; P. Altmeyer; M. Herde; H. Baumgärtl; D. W. Lübbers (2002). "The cutaneous uptake of atmospheric oxygen contributes significantly to the oxygen supply of human dermis and epidermis". The Journal of Physiology. 538 (3): 985-994. doi:10.1113/jphysiol.2001.013067. ISSN 0022-3751. PMC 2290093. PMID 11826181

5. "The human proteome in skin - The Human Protein Atlas". www.proteinatlas.org.

6. Uhlén, Mathias; Fagerberg, Linn; Hallström, Björn M.; Lindskog, Cecilia; Oksvold, Per; Mardinoglu, Adil; Sivertsson, Åsa; Kampf, Caroline; Sjöstedt, Evelina (23 January 2015). "Tissue-based map of the human proteome". Science. 347 (6220): 1260419. doi:10.1126/science.1260419. ISSN 0036-8075. PMID 25613900.

7. Edqvist, Per-Henrik D.; Fagerberg, Linn; Hallström, Björn M.; Danielsson, Angelika; Edlund, Karolina; Uhlén, Mathias; Pontén, Fredrik (19 November 2014). "Expression of Human Skin-Specific Genes Defined by Transcriptomics and Antibody-Based Profiling". Journal of Histochemistry\&Cytochemistry. 63 (2): 129-141. doi:10.1369/0022155414562646. PMC 4305515. PMID 25411189.

8. Muehlenbein, Michael (2010). Human Evolutionary Biology Cambridge University Press. pp. 192-213. ISBN 978-1139789004.

9. Jablonski, N.G. (2006). Skin: a Natural History. Berkeley: University of California Press. ISBN 978-0520954816.

10. Handbook of General Anatomy by B. D. Chaurasia. ISBN 978-81239-1654-5

11. "Pigmentation of Skin". Mananatomy.com. Retrieved 3 June 2019.

12. Webb, A.R. (2006). "Who, what, where, and when: influences on cutaneous vitamin D synthesis". Progress in Biophysics and $\begin{array}{llll}\text { Molecular } & \text { Biology. } & 92 & \text { (1): }\end{array}$ doi:10.1016/j.pbiomolbio.2006.02.004. PMID 16766240.

13. Jablonski, N.G.; Chaplin (2000). "The evolution of human skin coloration". Journal of Human Evolution. 39 (1): 57-106 doi:10.1006/jhev.2000.0403. PMID 10896812.

14. "The Fitzpatrick Skin Type Classification Scale". Skin Inc. (November 2007). Retrieved 7 January 2014.

15. "Fitzpatrick Skin Type"(PDF). Australian Radiation Protection and Nuclear Safety Agency. Archived from the original(PDF) on 31 March 2016. 7 January 2014

16. Alexiades-Armenakas, M. R., et al. The spectrum of laser skin resurfacing: nonablative, fractional, and ablative laser resurfacing. J Am AcadDermatol. 2008 May;58(5):719-37; quiz 738-40

17. Cutroneo, Kenneth R.; Kenneth M. Sterling (2004). "How do glucocorticoids compare to oligo decoys as inhibitors of collagen synthesis and potential toxicity of these therapeutics?". Journal of Cellular Biochemistry. 92 (1): 6-15. doi:10.1002/jcb.20030. ISSN 0730-2312. PMID 15095399.

18. Oikarinen, A. (2004). "Connective tissue and aging". Internationa Journal of Cosmetic Science. 26 (2): 107. doi:10.1111/j.14672494.2004.213_6.x. ISSN 0142-5463.

19. Gilchrest, BA (1990). "Skin aging and photoaging". Dermatology Nursing / Dermatology Nurses' Association. 2 (2): 79-82. PMID 2141531.

20. WI, Kenneth Todar, Madison. "Immune Defense against Bacterial Pathogens: Innate Immunity". Textbook of bacteriology.net. Retrieved 19 April 2017.

\section{AUTHORS PROFILE}

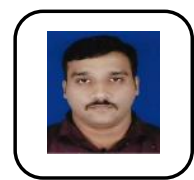

S. Sree Hari Raju,completed his M.Tech Computer Science \& Engineering and pursuing Ph.D from University of Mysore. His area of interest is in Image Processing, AI, Data Mining, Machine Learning.

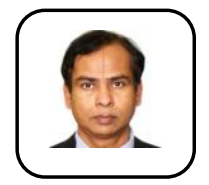

Dr. E G Rajan, done his Ph.D form IIT-Kanpur. His area of interest is in Signal and Image Processing, Data Mining, Machine Learning.

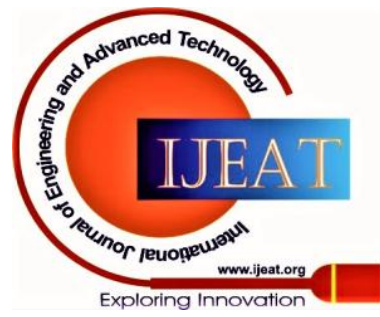

